\title{
Deep vein thrombosis and pulmonary embolism following lung resection
}

\author{
Styliani Maria Kolokotroni^^ \\ Department of Cardiothoracic Surgery, University Hospitals Coventry and Warwickshire, Coventry, UK \\ Correspondence to: Styliani Maria Kolokotroni. Department of Cardiothoracic Surgery, University Hospitals Coventry and Warwickshire, Coventry, \\ UK. Email: stmardel@yahoo.gr.
}

\begin{abstract}
Deep vein thrombosis (DVT) and pulmonary embolism (PE) are common complications in cancer. Patients with lung cancer have a risk of venous thromboembolism (VTE) of around 3\% over 2 years. The incidence of DVT after thoracic surgery is estimated to be between $0.4 \%$ and $51 \%$ and the incidence of PE between $1 \%$ and $5 \%$. The risk factors for VTE may be patient-related, cancer-related or treatmentrelated. Pneumonectomy is associated with a 3 -fold increase in post discharge VTE events compared to lobectomy. The diagnosis of VTE may be challenging as it has few specific symptoms. For this reason, prophylactic treatment with low molecular weight heparin or unfractioned heparin and antiembolism stockings or intermittent pneumatic compression devices are widely recommended for patients at risk for VTE. Patients who undergo thoracic surgery are deemed at high risk for postoperative VTE as a significant proportion of them have cancer, underlying respiratory and cardiovascular comorbidities, and are of advanced age. Extended VTE prophylaxis may be considered as there is a risk of developing VTE post discharge. Risk-assessment models for VTE can be utilized in thoracic surgery and the Caprini riskassessment model has been used successfully in the USA. Postoperative PE needs to be diagnosed and treated promptly as delay may be fatal. It is managed with anticoagulants but thrombolysis should be considered in compromised patients.
\end{abstract}

Keywords: Lung cancer; pulmonary embolism; deep vein thrombosis (DVT); lung resection

Received: 06 July 2020; Accepted: 22 September 2020; Published: 10 July 2021.

doi: $10.21037 /$ shc-20-68

View this article at: http://dx.doi.org/10.21037/shc-20-68

\section{Introduction}

Venous thromboembolism (VTE), which contains deep vein thrombosis (DVT) and pulmonary embolism (PE), is one of the most common complications in cancer as well as a major surgery-related complication (1). Malignancy has been associated with a 6 to 7 -fold increased risk of DVT and a 3 -fold increased risk of $\mathrm{PE}$. The reported incidence of VTE among cancer patients is $10-20 \%$, and up to $10 \%$ of patients with idiopathic VTE will be diagnosed with occult cancer or develop symptomatic cancer (2). However, the risk may vary considerably between different types of cancer. DVT rates may range between $2 \%$ and $34 \%$ among patients with different types of localised cancer and the rates are higher in metastatic cancer. The incidence of VTE following lung resection is $2.3 \%$. The highest levels are encountered in oesophagectomy with an incidence of $7.3 \%$ (3). The incidence of DVT after thoracic surgery is estimated to be between $0.4 \%$ and $51 \%$ and the incidence of PE between $1 \%$ and $5 \%$ with $2 \%$ being fatal (4). This variation may be due to differences in the detection method as in post-operative screening versus symptomatic detection and the type and/or duration of thromboprophylaxis (5).

VTE can still occur to $0.8-7.4 \%$ of patients who undergo thoracic surgery despite thromboprophylaxis

^ ORCID: 0000-0002-0384-065X. 
$(6,7)$. Dentali et al. (8), found a $1.7 \%$ incidence of VTE in patients who underwent thoracotomy for lung cancer despite administration of heparin. Agrazian et al. (9) screened patients operated for lung cancer and found $12.1 \%$ prevalence of VTE with $5.2 \%$ mortality rate. Most events were asymptomatic.

The patients who are diagnosed with lung cancer have a risk of DVT or PE estimated at around 3\% over 2 years (10). Patients who undergo surgery have a two to three-fold increased risk of VTE compared to the patients who do not undergo surgery. Cancer patients who undergo the same thoracic surgical procedure have at least double risk of DVT and 3-fold risk of fatal PE compared to patients who do not have cancer(11).

VTE can cause increased bleeding, delay in chemotherapy, increased costs and risk of VTE recurrence. DVT can cause post-thrombotic syndrome due to damage of the venous valves which can affect quality of life. $10 \%$ of the patients who present with symptomatic PE will die in the first hour, and the patients who survive are at high risk for right heart failure and right heart strain(12).

VTE is the most common cause of death in postoperative cancer patients within 30 days of surgery, is associated with poorer longer-term prognosis, and can increase mortality from $1.2 \%$ to $8 \%$ (13). Yang et al. (14), found that the highest incidence of VTE was within one month after the procedure.

Patients who undergo pneumonectomy, have a peak incidence of VTE on the $6^{\text {th }}$ or $7^{\text {th }}$ postoperative day $(15,16)$, when a significant amount of the patients will have been discharged from the hospital. The risk remains high until post-operative day 30; therefore, routine screening and extended prophylaxis in this cohort of patients may be considered.

\section{Risk factors}

Rudolf Virchow suggested the three main causes of VTE in 1888: vascular endothelial damage, stasis and hypercoagulability (17). Hypercoagulability in cancer may be related to cytokine signalling, abnormal fibrinolysis, dysfunctional platelet adhesion and overexpression of tissue factor $(18,19)$.

The risks that can contribute to VTE in lung cancer patients are multifactorial and can be patient-specific and/ or related to biological parameters, related to the type of cancer or the presence of metastases, related to the treatment (surgery, chemotherapy, radiotherapy), or related to all of them (13).

Patient-specific risk factors for VTE include age, gender, smoking history, race, BMI $>25 \mathrm{~kg} / \mathrm{m}^{2}$, prolonged immobility, higher performance status, past medical history, presence of varicose veins, serious lung disease or chronic respiratory insufficiency, pre-existing cardiac conditions, pregnancy, thrombophilia, previous history of $\mathrm{PE}$, congestive heart failure, or trauma $(14,18,20-23)$. Asian population may have a lower incidence of VTE which may be due to lower prevalence of factor $\mathrm{V}$ Leiden mutation and possibly lower levels of fibrinogen, factor VIIc and factor VIIIc (24). However, a recent study in China (22), found an overall incidence of VTE of $11.2 \%$ after lung surgery (without VTE prophylaxis which is not used routinely in China) and none of the patients had typical symptoms of VTE.

Tumour biology, histologic features and stage of the disease could be related to VTE (25). Postoperative VTE incidence is higher with late stage cancer (stage IV vs. stage I) which is an independent risk factor for postoperative VTE (14).

Radiotherapy and chemotherapy in lung cancer patients may lead to deficiency in protein $\mathrm{C}$, protein $\mathrm{S}$ and antithrombin III, all of which contribute to thrombus formation (13). PICC catheter, which may lead to clot formation, postoperative use of antiangiogenesis drugs EGFR/TKI treatment, no EPO treatment, and preoperative increase in D-dimer levels (26) may all increase the risk of VTE (14).

Surgery for lung cancer is an independent risk factor. On the other hand, patients who have surgery for lung cancer with curative intent are most likely to have earlystage lung cancer and therefore they could express lower hypercoagulability (7). The patients who undergo lung resection may present a different VTE profile than the general oncology and orthopaedic patients with a higher rate of denovo PE; in this situation, DVT screening only many miss a significant proportion of $\mathrm{PE}$.

Longer operative time, intraoperative bleeding and extent of surgical injury, increased ASA score, incomplete resection (14) and open surgery versus thoracoscopic surgery, $0.8 \%$ versus $0.6 \%$, are all correlated to higher chance of VTE $(25,27)$. The extent of the resection is also a risk factor for VTE; pneumonectomy is associated with 3 -fold increase in the incidence of VTE post discharge compared to lobectomy, $2 \%$ versus $0.6 \%, \mathrm{P}<0.01$ (17). Factors related to the surgical technique, involving manipulation of the pulmonary arteries and division of arterial branches may have a role in formation of thrombi. 
Daddi et al. (28) showed that $74 \%$ of $\mathrm{PE}$ events were found without DVT, potentially because of direct injury to the pulmonary vessels. Additionally, the risk could be higher due to prolonged periods of bed rest and reduced postoperative mobility due to pain (14).

The use of neuraxial and general anaesthesia instead of sole general anaesthesia in open lung surgery has been associated with increased risk of VTE possibly due to the reduced use of anticoagulants in the first group of patients for fear of neuraxial haematoma formation (29). Moreover, recent steroid use, blood transfusions, and postoperative complications such as wound infection, reintubation, peripheral nerve injury, postoperative sepsis and extended length of stay may increase the risk of DVT (3). PE is associated with recent radiation treatment, thrombocytosis (platelet count $\geq 400,000$ ), and postoperative complications such as wound infection, reintubation, DVT, urinary tract infection, and cardiac arrest (3).

\section{Diagnosis}

Diagnosing VTE may be challenging as it has few specific symptoms. Perioperative or postoperative VTE may be asymptomatic which could explain the low incidence of postoperative VTE reported in patients after thoracic surgery (22).

Postoperative VTE is defined as the presence of DVT and/or PE during the postoperative period.

DVT may be asymptomatic or present with calf pain. According to the American College of Surgeons National Surgical Quality Improvement Program (ACS NSQIP) $(25,30)$, postoperative DVT is defined as a blood clot or thrombus in a deep vein of any limb identified up to 30 days after the operative procedure with both of the following: (I) new diagnosis of DVT confirmed by colour Doppler ultrasound examination, venogram, CT or any other definitive imaging modality including direct pathological examination such as autopsy and (II) the need for anticoagulation treatment or placement of an inferior vena cava filter or clipping the vena cava or indication in the patient's records that the patient required treatment but no additional option was available.

$\mathrm{PE}$ is most frequently attributed to DVT of the lower limbs where the clot travels to the pulmonary artery through the circulation. PE can occur rarely due to air embolism, tumour, or bone marrow fat.

The clinical presentation of PE may vary from asymptomatic to right heart failure, hypoxaemia, cardiogenic shock and death. Pulmonary embolism severity index (PESI) and simplified PESI are models that have been suggested to predict short- and long-term mortality (31). Signs and symptoms that suggest pulmonary embolism are: sudden onset of shortness of breath, pleuritic chest pain, syncope, haemoptysis, rales, tachycardia/arrhythmia, cyanosis, lightheadedness, hypotension, sweating, calf pain, persistent hypoxaemia. Additional signs are shock, RV dysfunction as evidence of RV dilatation on echocardiography, hypopokinesia or pressure overload, increase of BNP or N terminal pro-BNP, and raised right heart pressure at right heart catheterization, RV dilatation on CT, and positive cardiac troponin T or I (marking myocardial injury) (32). Arterial blood gas analysis shows decreased $\mathrm{PaO} 2, \mathrm{SO} 2$, and $\mathrm{PaCO} 2$ and increase in the alveolar- arterial oxygen pressure gradient $\mathrm{p}(\mathrm{A}-\mathrm{a}) \mathrm{O}_{2}$.

Postoperative $\mathrm{PE}$ is identified up to 30 days after the operation with both of the following: a) new diagnosis of a blood clot in a pulmonary artery with subsequent obstruction of blood supply to the lung parenchyma and b) V/Q scan which indicates a high probability of $\mathrm{PE}$ or a positive result identified on CT, TOE, pulmonary angiography, CT angiography with pulmonary embolism protocol or any other definitive imaging modality including direct pathological examination such as autopsy (25). CXR is non-specific. Echocardiography may demonstrate dilatation of the right ventricle, SPAP $>40 \mathrm{mmHg}$, or tricuspid regurgitation. The gold-standard tool for diagnosis of $\mathrm{PE}$ is computed tomography chest angiography with pulmonary embolism protocol (CTPA), if immediately available and in a stable patient who is normotensive and with no shock. CTPA has a positive predicted value of up to $97 \%$ in the main or lobar pulmonary arteries and $68 \%$ in the segmental arteries (33). Ventilation/perfusion scan and MRI have been used with limited accuracy in detection of PE. According to the European Society of Cardiology, in patients with suspected $\mathrm{PE}$ and who present with shock or hypotension, if CT scan is not readily available or they are too unstable for a CT, echocardiography may be helpful. If there are no signs of RV overload or dysfunction on the echocardiogram in a patient who is hypotensive and in shock, PE can be excluded as a cause of haemodynamic compromise. D-dimer in combination with clinical assessment can rule out $\mathrm{PE}$ as diagnosis in $30 \%$ of the cases (32). However, increased d-dimer levels are not specific for PE as they can also be elevated in trauma, recent surgery, trauma, pregnancy, cancer, inflammation and advanced age. Elevated troponin $\mathrm{I}$, troponin $\mathrm{T}$ and BNP are associated with increased 
mortality, as they indicate right ventricular failure. WBC levels tend to be raised and INR tends to be low.

The presence of shock, hypotension, RV dysfunction and/or elevated troponin is associated with high mortality from PE (>15\%) and thrombolysis or embolectomy may be indicated. If there are signs of RV dysfunction and/or myocardial injury, the mortality is $3-15 \%$. When none of these risk factors are present, early mortality from $\mathrm{PE}$ is $<1 \%(32)$.

Given that the diagnosis of DVT or PE is often subtle or subclinical, clinicians must be very vigilant and have a low threshold for investigations on clinical suspicion.

\section{Perioperative prevention}

Low molecular weight heparin (LMWH) is widely recommended for VTE prophylaxis in patients undergoing surgery for cancer $(34,35)$; however, the evidence for using it is mostly based on observational studies. VTE chemical prophylaxis regimen varies widely among centres regarding both duration and choice of pharmacological agent, which is likely due to the small amount of data specifically targeted to thoracic surgery patients (5). The majority of surgeons in the USA do provide pharmacological thromboprophylaxis to patients who undergo lung resection but they do not provide extended VTE prophylaxis post discharge. Most of the surgeons believe that VTE prophylaxis is safe and not related to any additional postoperative bleeding events (36). It is widely felt that the prevention of severe and potentially fatal $\mathrm{PE}$ outweighs the risks of postoperative bleeding.

Christensen et al. (6) performed a systematic literature review of 19 studies and 10,660 patients to assess the risk of VTE peri- and postoperatively in patients undergoing surgery for primary lung cancer with curative intent. The patients underwent either thoracotomy or VATS and either wedge resection, segmentectomy, lobectomy or pneumonectomy. The risk of VTE ranged between $0.2-19 \%$ with overall mean risk of $2 \%$. The risk was $2.1 \%$ in the studies with 1 month follow up and $2.8 \%$ in studies with follow up greater than 1 month. This could suggest that the greatest risk for VTE is in the immediate postoperative period with reduced risk thereafter. The same group, in their randomised controlled trial (37), found no difference in the coagulation profile of VATS lobectomy patients who either received LMWH once daily or no LMWH at all.

Attaran et al. (7) suggested that thromboelastography could be used as screening for hyper-coagulopathic patients to provide thromboprophylaxis. Mulder et al. suggested the use of rotational thromboelastometry (ROTEM), a viscoelastic test which can be used to assess coagulation and hypercoagulability (38) and is more sensitive in detection of coagulopathy than conventional coagulation. Hypercoagulability tends to be reversed after surgical resection; however, it tends to persist at least one to two weeks after surgery. This supports extended duration thromboprophylaxis regimens. ROTEM data may be useful for implementation in a risk assessment model.

Adverse side effects of LMWH may be thrombocytopaenia, epistaxis, gastrointestinal bleeding and wound haematoma (20). Unfractioned heparin is effective in preventing postoperative VTE without adverse events related to epidural catheters or heparin-induced thrombocytopaenia (39). The use of intermittent pneumatic compression has been shown to be effective in preventing pulmonary embolism post thoracic surgery (40). Fondaparinux may lead to more bleeding events post-surgery and hence the increased requirements for transfusions or re-exploration compared to enoxaparin (41), while it does not seem to provide a benefit to the risk of symptomatic postoperative PE.

Panucci et al. (42) studied whether the standard prophylactic dose of enoxaparin $40 \mathrm{mg}$ once a day is adequate for patients undergoing thoracic surgical procedures. The anticoagulant effect of enoxaparin can be monitored by calculating anti-factor $\mathrm{Xa}(\mathrm{aFXa})$ levels, and it is considered adequate if the peak levels of aFXa are $0.3-0.5 \mathrm{IU} / \mathrm{mL}$, as measured 4 hours after administration of enoxaparin once in steady state, usually after the $3^{\text {rd }}$ dose. They found that only $30 \%$ of the patients had adequate peak aFXa levels and two thirds of the patients had undetectable level on anticoagulation 12 hours post dose. A weight-based dose as opposed to a fixed dose may be of benefit. This has been shown to be beneficial in patients who undergo surgery for trauma (43).

Dong et al. (1), compared LMWH combined with mechanical prophylaxis, with intermittent pneumatic compression and elastic stockings, against mechanical prophylaxis only for inpatients who underwent thoracotomy for lung or oesophageal cancer-with moderate risk of VTE-and they did not find that the first group had better results in VTE incidence or length of hospital stay. There were no bleeding events in the LMWH group.

The American College of Chest Physicians (ACCP, $9^{\text {th }}$ edition) (12) and the American Society of Clinical Oncology (44) guidelines recommend LMWH for all patients undergoing surgical procedures for cancer starting either preoperatively or as soon as possible after the 
procedure for at least 7-10 days, which may be extended for 4 weeks in high-risk patients with history of VTE, high BMI, or postoperative residual lesions (14). For patients who undergo thoracic surgery, mechanical and pharmacological prophylaxis, with low dose unfractioned heparin or $\mathrm{LMWH}$ is recommended as the benefit of prevention of VTE episodes outweighs the risk of bleeding (12).

NICE $(32,45)$ guidelines recommend initiating mechanical VTE prophylaxis (elastic stockings, intermittent pneumatic compression devices or foot impulse devices) upon admission and continuing their use until the patient is fully mobile. Pharmacological VTE prophylaxis with LMWH once daily or in divided doses twice daily, or unfractionated heparin in patients with renal failure, should be added in patients who have a low risk of major bleeding. For patients at high risk of bleeding, mechanical VTE prophylaxis is recommended. Additionally, the insertion or removal of epidural catheters should not occur within $12 \mathrm{~h}$ of heparin administration (46).

The Enhanced Recovery After Surgery (ERAS) guidelines (47) suggest that patients who undergo major lung resection should be given pharmacological and mechanical VTE prophylaxis. Extended administration of $\mathrm{LMWH}$ for up to 4 weeks is suggested for patients at high risk of VTE.

The European Society of Medical Oncology recommends that patients who undergo thoracotomy or thoracoscopy that lasts more than 30 minutes should be considered for LMWH (48).

The European Society of Anaesthesiology recommends that patients who undergo thoracic surgery for presumed benign disease should receive mechanical prophylaxis with intermittent pneumatic stockings as they have low risk for VTE (Grade 2C), whereas patients with the diagnosis of primary or metastatic cancer should be considered high-risk for VTE (with equally high risk of bleeding) and pharmacological as well as mechanical prophylaxis is recommended (Grade 2B) (49).

\section{Extended VTE prophylaxis and risk-assessment models}

Patients undergoing thoracic surgery are at risk of post discharge VTE $(6,33,50)$ with the highest incidence appearing within 30 days after the procedure (20). In patients undergoing pneumonectomy for cancer, the incidence of VTE peaks on the $6^{\text {th }}$ or $7^{\text {th }}$ post operative day. Furthermore, the presence of VTE is a negative prognostic factor for long-term survival (16).
Thomas et al. (25) found that age $>65$ years, male sex, ASA of 4 and history of COPD were associated with an increased risk of post discharge VTE. Almost half of VTE events were reported post discharge. Patients with VTE that occurred before discharge were more likely to be readmitted, and patients with post discharge VTE had a fourfold increased risk for readmission. In a retrospective review of 232 lung resections for cancer, the rate of VTE was $5.2 \%$ with one-third occurring post discharge (51). In a recent prospective cohort study of 157 patients who were screened for VTE with CTPA and venous US Doppler one month postoperatively, VTE (symptomatic or not) was found in $12.1 \%$ of them (9).

Various studies have reported that the extension of pharmacological prophylaxis up to one month after surgery decreases the risk of VTE in major surgery for cancer $(52,53)$. Currently, there is no evidence to support the use of oral pharmacological VTE prophylaxis. Despite this, administration of extended VTE prophylaxis in thoracic surgery patients varies widely between surgeons, centres and specialties (5). There is so far no prospective, randomized controlled trial in thoracic surgery to examine the potential benefit of extended, out-of-hospital postoperative VTE prophylaxis.

The introduction of a risk-assessment model or nomogram could be initiated in all patients so that they receive a tailor-made thromboprophylaxis, adjusted to their pre- and postoperative risk factors.

The Caprini risk assessment model (RAM) (54) (Figure 1: Updated Caprini risk-assessment model) which consists of patient risk stratification and extended postoperative VTE prophylaxis with LMWH has been suggested for lung cancer and has been used in the USA (20). Based on the score, patients are categorised as low risk (score 0-4) with no need of extended VTE prophylaxis, moderate risk (score 5-8) with recommendation for 10 days of extended prophylaxis and high risk (score $\geq 9$ ) with need for 30 days of extended prophylaxis. Hackey et al. (51) found that thoracic surgery patients with a high Caprini score had a higher incidence of post-operative VTE events. They introduced (56) extended VTE prophylaxis according to the Caprini score. Patients demonstrated an excellent adherence $(97.2 \%)$ to postdischarge enoxaparin prophylaxis, and the study reported an overall VTE rate of $2.3 \%$ with no post-discharge VTE or bleeding events. Similarly, Sterbing et al. (20) found that VTE rates dropped from $7 \%$ to $3 \%$ once the Caprini model was implemented with no adverse bleeding events. 


\begin{tabular}{|c|c|c|c|}
\hline $\begin{array}{l}1 \text { point for each risk factor that } \\
\text { apply now or within the past month } \\
\text { - Age } 40-60 \text { years } \\
\text { - Minor surgery (<45 minutes) } \\
\text { planned } \\
\text { - BMI } \geq 30 \mathrm{~kg} / \mathrm{m}^{2} \\
\text { - Major surgery (>45 minutes) within } \\
\text { the last month } \\
\text { - Swollen legs (current) } \\
\text { - Visible varicose veins } \\
\text { - Sepsis } \\
\text { - COPD } \\
\text { - Acute myocardial infarction } \\
\text { - Congestive heart failure } \\
\text { - History of Inflammatory Bowel } \\
\text { Disease } \\
\text { - Bed rest or restricted mobility }\end{array}$ & $\begin{array}{l}2 \text { points for each risk factor } \\
\text { - Age } 61-74 \text { years } \\
\text { - Major open or keyhole surgery } \\
\text { (>45 minutes) } \\
\text { - Prior or present cancer (excluding } \\
\text { non melanoma skin cancer, breast } \\
\text { and thyroid cancer) } \\
\text { - Immobilising plaster cast } \\
\text { - Central venous access } \\
\text { - Confined to bed for } \leq 72 \text { hours }\end{array}$ & $\begin{array}{l}3 \text { points for each risk factor } \\
\text { - Age } \geq 75 \text { years } \\
\text { - History or family history of VTE } \\
\text { - Current chemotherapy } \\
\text { - Positive Factor V Leiden/ } \\
\text { Prothrombin } 20210 A / L u p u s \\
\text { anticoagulant } \\
\text { - Elevated anticardiolipin antibodies } \\
\text { or serum homocysteine HIT } \\
\text { - Other congenital or acquired } \\
\text { thrombophilias }\end{array}$ & $\begin{array}{l}5 \text { points for each risk factor that } \\
\text { apply now or within the past month } \\
\text { - Major surgery lasting more than } \\
6 \text { hours } \\
\text { - Stroke } \\
\text { - Elective hip or knee arthroplasty } \\
\text { - Hip, pelvis, leg fracture } \\
\text { - Acute spinal cord fracture or } \\
\text { paralysis } \\
\text { - Multiple traumas }\end{array}$ \\
\hline \multirow{3}{*}{\multicolumn{2}{|c|}{$\begin{array}{l}\text { For women only (1 point each) } \\
\text { - Pregnant or post-partum } \\
\text { - History of unexplained or recurrent spontaneous abortion } \\
\text { - Oral contraceptives or HRT }\end{array}$}} & $0-4$ & Low \\
\hline & & $5-8$ & Moderate \\
\hline & & $\geq 9$ & High \\
\hline
\end{tabular}

Figure 1 Updated Caprini risk-assessment model (55).

Other suggested risk assessment models for VTE include Rogers RAM (57) for surgical patients excluding orthopaedic surgery, Padua RAM (58) for medical patients and Khorana RAM (59) for oncology patients. The ChaoYang VTE RAM (26) is a RAM which has been suggested for patients undergoing thoracic surgery in China. This model found that age $\geq 60$, ASA $\geq 2$, open surgery, operative time $>180 \mathrm{~min}$, intraoperative bleeding $>200 \mathrm{~mL}$, D-dimer $>0.55 \mathrm{~mL} / \mathrm{L}, \mathrm{RBC}<4.0 \times 10^{12} / \mathrm{L}$ and $\mathrm{BMI}>30 \mathrm{~kg} / \mathrm{m}^{2}$ were independent risk factors for VTE.

Shah et al. (60) suggested nomograms that allow individualised risk assessment for postoperative VTE and post discharge VTE in patients post abdominal or thoracic surgery, to identify those patients who are at higher risk for postoperative VTE, given the significant variation in the incidence of VTE depending on patient and procedural factors.

Novis et al. (61), implemented a computerised DVT risk-assessment tool for surgical patients and they found that the number of patients who received appropriate thromboprophylaxis more than doubled and that there was an $80 \%$ decrease in the incidence of postoperative DVT rate, when the tool was used.

This suggests that implementing a standardised DVT risk assessment computerised tool can increase the appropriate use of thromboprophylaxis accordingly with a subsequent decrease in VTE events.

\section{Management of postoperative DVT/PE}

In cancer patients with VTE, ACCP guidelines $(62,63)$ suggest $\mathrm{LMWH}$ over vitamin $\mathrm{K}$ antagonists, dabigatran, rivaroxaban, apixaban, or edoxaban. For patients with DVT the routine use of compression stockings is not recommended to prevent post-thrombotic syndrome.

The recommended period of anticoagulation for proximal DVT or PE of provoked by surgery is 3 months and it is preferred over a shorter period.

Acute PE needs to be diagnosed and treated promptly as delay may be fatal $(23,64)$. Haemodynamic and respiratory support is necessary in patients with confirmed or suspected $\mathrm{PE}$ and shock or hypotension (32).

Once $\mathrm{PE}$ is diagnosed or there is a high suspicion of $\mathrm{PE}$, the use of any anticoagulant therapy with either LMWH, unfractioned heparin, or fondaparinux must be initiated (65). Supplementary oxygen should be given as well. Bleeding may be of concern, therefore the patients should be monitored closely, as blood transfusions may be necessary. If there is evidence of DVT in the lower limbs, an inferior vena cava filter may be considered. 
Thrombolysis with urokinase or recombinant tissue plasminogen activator is advised as first-line treatment in patients with $\mathrm{PE}$ and persistent hypotension and/or cardiogenic shock, as it has been shown to be effective in resolving thromboembolic obstruction and improving haemodynamic parameters $(32,62,63)$. However, thrombolysis should be avoided in patients with low risk of $\mathrm{PE}$ and considered with caution in patients with intermediate risk for $\mathrm{PE}$ and in pre-existing factors for increased risk of bleeding, as history of haemorrhagic stroke, ischemic stroke the last 6 months, central nervous system damage or neoplasm, recent major trauma, surgery or head injury within preceding 3 weeks, gastrointestinal bleeding within the last month, known bleeding.

Embolectomy can be lifesaving and indicated in the failure of medical therapy, as in persistent systemic hypotension with shock that can lead to death before thrombolysis can act (66), massive PE with RV dysfunction and worsening respiratory failure, contraindication to use anticoagulation/thrombolysis with high risk of bleeding, failed thrombolysis or poor response. Mortality can be as high as $30 \%(23,67)$. Usually pulmonary endarterectomy is applied to patients with chronic thromboembolic pulmonary hypertension (CTEPH) (68).

\section{Conclusion}

Patients who undergo thoracic surgery patients are deemed at high risk for DVT and/or PE. Pharmacologic thromboprophylaxis (69) with LMWH, unfractioned heparin or fondaparinux is recommended for patients who undergo major thoracic surgery and have no increased risk of bleeding. Patients with increased risk of bleeding should have mechanical thromboprophylaxis. Extended pharmacologic prophylaxis for up to 28 days should be considered in patients with risk factors who undergo major surgery for cancer.

Patients with high probability or confirmed PE should be started on anticoagulation without delay. Thrombolysis should be considered in PE with cardiogenic shock or persistent hypotension.

There is a need for universal guidelines specifically targeted to thoracic surgery patients to prevent postoperative VTE and its complications. Randomized controlled trials and the introduction of risk assessment models to assess the potential benefit of extended post-discharge VTE prophylaxis may be beneficial.

\section{Acknowledgments}

Funding: None.

\section{Footnote}

Provenance and Peer Review: This article was commissioned by the Guest Editor (David Waller) for the series "Complications of Thoracic Surgery - aetiology, management and prevention" published in Shanghai Chest. The article has undergone external peer review.

Conflicts of Interest: The author has completed the ICMJE uniform disclosure form (available at: http://dx.doi. org/10.21037/shc-20-68). The series "Complications of Thoracic Surgery - aetiology, management and prevention" was commissioned by the editorial office without any funding or sponsorship. The author has no other conflicts of interest to declare.

Ethical Statement: The author is accountable for all aspects of the work in ensuring that questions related to the accuracy or integrity of any part of the work are appropriately investigated and resolved.

Open Access Statement: This is an Open Access article distributed in accordance with the Creative Commons Attribution-NonCommercial-NoDerivs 4.0 International License (CC BY-NC-ND 4.0), which permits the noncommercial replication and distribution of the article with the strict proviso that no changes or edits are made and the original work is properly cited (including links to both the formal publication through the relevant DOI and the license). See: https://creativecommons.org/licenses/by-nc-nd/4.0/.

\section{References}

1. Dong J, Wang J, Feng Y, et al. Effect of low molecular weight heparin on venous thromboembolism disease in thoracotomy patients with cancer. J Thorac Dis 2018;10:1850-6.

2. Auer RA, Scheer AS, McSparron JI, et al. Postoperative venous thromboembolism predicts survival in cancer patients. Ann Surg 2012;255:963-70.

3. De Martino RR, Goodney PP, Spangler EL, et al. Variation in thromboembolic complications among patients undergoing commonly performed cancer operations. J Vasc Surg 2012;55:1035-1040.e4. 
4. Di Nisio M, Peinemann F, Porreca E, et al. Primary prophylaxis for venous thromboembolism in patients undergoing cardiac or thoracic surgery. Cochrane Database Syst Rev 2015;(6):CD009658.

5. Agzarian J, Linkins LA, Schneider L, et al. Practice patterns in venous thromboembolism (VTE) prophylaxis in thoracic surgery: a comprehensive Canadian Delphi survey. J Thorac Dis 2017;9:80-7.

6. Christensen TD, Vad H, Pedersen S, et al. Venous thromboembolism in patients undergoing operations for lung cancer: a systematic review. Ann Thorac Surg 2014;97:394-400.

7. Attaran S, Somov P, Awad WI. Randomised high- and low-dose heparin prophylaxis in patients undergoing thoracotomy for benign and malignant disease: effect on thrombo-elastography. Eur J Cardiothorac Surg 2010;37:1384-90.

8. Dentali F, Malato A, Ageno W, et al. Incidence of venous thromboembolism in patients undergoing thoracotomy for lung cancer. J Thorac Cardiovasc Surg 2008;135:705-6.

9. Agzarian J, Hanna WC, Schneider L, et al. Postdischarge venous thromboembolic complications following pulmonary oncologic resection: An underdetected problem. J Thorac Cardiovasc Surg 2016;151:992-9.

10. Chew HK, Davies AM, Wun T, et al. The incidence of venous thromboembolism among patients with primary lung cancer. J Thromb Haemost 2008;6:601-8.

11. Tesselaar ME, Osanto S. Risk of venous thromboembolism in lung cancer. Curr Opin Pulm Med 2007;13:362-7.

12. Gould MK, Garcia DA, Wren SM, et al. Prevention of VTE in nonorthopedic surgical patients: Antithrombotic Therapy and Prevention of Thrombosis, 9th ed: American College of Chest Physicians Evidence-Based Clinical Practice Guidelines [published correction appears in Chest. 2012 May;141(5):1369]. Chest 2012;141:e227S-e277S.

13. Corrales-Rodriguez L, Blais N. Lung cancer associated venous thromboembolic disease: a comprehensive review. Lung Cancer 2012;75:1-8.

14. Yang Y, Zhou Z, Niu XM, et al. Clinical analysis of postoperative venous thromboembolism risk factors in lung cancer patients. J Surg Oncol 2012;106:736-41.

15. Mason DP, Quader MA, Blackstone EH, et al.

Thromboembolism after pneumonectomy for malignancy: an independent marker of poor outcome. J Thorac Cardiovasc Surg 2006;131:711-8.

16. Raja S, Idrees JJ, Blackstone EH, et al. Routine venous thromboembolism screening after pneumonectomy: The more you look, the more you see. J Thorac Cardiovasc
Surg 2016;152:524-532.e2.

17. Gómez-Hernández MT, Rodríguez-Pérez M, NovoaValentín N, et al. Prevalence of venous thromboembolism in elective thoracic surgery. Arch Bronconeumol 2013;49:297-302.

18. Marinho FC, Takagaki TY. Hypercoagulability and lung cancer. J Bras Pneumol 2008;34:312-22.

19. Osborne NH, Wakefield TW, Henke PK. Venous thromboembolism in cancer patients undergoing major surgery. Ann Surg Oncol 2008;15:3567-78.

20. Sterbling HM, Rosen AK, Hachey KJ, et al. Caprini Risk Model Decreases Venous Thromboembolism Rates in Thoracic Surgery Cancer Patients. Ann Thorac Surg 2018;105:879-85.

21. Hicks LK, Cheung MC, Ding K, et al. Venous thromboembolism and nonsmall cell lung cancer: a pooled analysis of National Cancer Institute of Canada Clinical Trials Group trials. Cancer 2009;115:5516-25.

22. Song C, Shargall Y, Li H, et al. Prevalence of venous thromboembolism after lung surgery in China: a singlecentre, prospective cohort study involving patients undergoing lung resections without perioperative venous thromboembolism prophylaxis $\uparrow$. Eur J Cardiothorac Surg 2019;55:455-60.

23. Shonyela FS, Yang S, Liu B, et al. Postoperative Acute Pulmonary Embolism Following Pulmonary Resections. Ann Thorac Cardiovasc Surg 2015;21:409-17.

24. Jakhetiya A, Shukla NK, Deo SV, et al. Deep Vein Thrombosis in Indian Cancer Patients Undergoing Major Thoracic and Abdomino-Pelvic Surgery. Indian J Surg Oncol 2016;7:425-9.

25. Thomas DC, Arnold BN, Hoag JR, et al. Timing and Risk Factors Associated With Venous Thromboembolism After Lung Cancer Resection. Ann Thorac Surg 2018;105:1469-75.

26. Tian B, Li H, Cui S, et al. A novel risk assessment model for venous thromboembolism after major thoracic surgery: a Chinese single-center study. J Thorac Dis 2019;11:1903-10.

27. Kim JY, Khavanin N, Rambachan A, et al. Surgical duration and risk of venous thromboembolism. JAMA Surg 2015;150:110-7.

28. Daddi G, Milillo G, Lupattelli L, et al. Postoperative pulmonary embolism detected with multislice computed tomography in lung surgery for cancer. J Thorac Cardiovasc Surg 2006;132:197-8.

29. Özbek U, Poeran J, Mazumdar M, et al. Patient Safety and Comparative Effectiveness of Anesthetic Technique in Open Lung Resections. Chest 2015;148:722-30. 
30. American College of Surgeons. National Surgical Quality. Improvement Program. Available online: http://www. acsnsqip.org

31. Kilic T, Gunen H, Gulbas G, et al. Prognostic role of simplified Pulmonary Embolism Severity Index and the European Society of Cardiology Prognostic Model in short- and long-term risk stratification in pulmonary embolism. PakJ Med Sci 2014;30:1259-64.

32. Brunelli A. Deep vein thrombosis/pulmonary embolism: prophylaxis, diagnosis, and management. Thorac Surg Clin 2012;22:25-8, v.

33. Lapner ST, Kearon C. Diagnosis and management of pulmonary embolism. BMJ 2013;346:f757.

34. Farge D, Debourdeau P, Beckers M, et al. International clinical practice guidelines for the treatment and prophylaxis of venous thromboembolism in patients with cancer. J Thromb Haemost 2013;11:56-70.

35. Lyman GH, Bohlke K, Falanga A; American Society of Clinical Oncology. Venous thromboembolism prophylaxis and treatment in patients with cancer: American Society of Clinical Oncology clinical practice guideline update. J Oncol Pract 2015;11:e442-e444.

36. Malgor RD, Bilfinger TV, Blebea J, et al. Perception of Chemical Venous Thromboprophylaxis for Oncologic Lung Resections among Thoracic Surgeons. Ann Vasc Surg 2017;44:299-306.

37. Christensen TD, Vad H, Pedersen S, et al. Coagulation profile in patients undergoing video-assisted thoracoscopic lobectomy: A randomized, controlled trial. PLoS One 2017;12:e0171809.

38. Mulder MB, Proctor KG, Valle EJ, et al. Hypercoagulability After Resection of Thoracic Malignancy: A Prospective Evaluation. World J Surg 2019;43:3232-8.

39. Yoshida J, Inoue M, Furugaki K, et al. Pulmonary thromboembolism in lung surgery: use of unfractionated heparin. Asian Cardiovasc Thorac Ann 2014;22:46-8.

40. Nagahiro I, Andou A, Aoe M, et al. Intermittent pneumatic compression is effective in preventing symptomatic pulmonary embolism after thoracic surgery. Surg Today 2004;34:6-10.

41. Girard P, Demaria J, Lillo-Le Louët A, et al. Transfusions, major bleeding, and prevention of venous thromboembolism with enoxaparin or fondaparinux in thoracic surgery. Thromb Haemost 2011;106:1109-16.

42. Pannucci CJ, Fleming KI, Holoyda K, et al. Enoxaparin 40 mg per Day Is Inadequate for Venous Thromboembolism Prophylaxis After Thoracic Surgical Procedure. Ann
Thorac Surg 2018;106:404-11.

43. Berndtson AE, Costantini TW, Lane J, et al. If some is good, more is better: An enoxaparin dosing strategy to improve pharmacologic venous thromboembolism prophylaxis. J Trauma Acute Care Surg 2016;81:1095-100.

44. Lyman GH, Kuderer NM; American Society of Clinical Oncology. Prevention and treatment of venous thromboembolism among patients with cancer: the American Society of Clinical Oncology Guidelines. Thromb Res 2010;125 Suppl 2:S120-7.

45. Venous thromboembolism in over 16s: reducing the risk of hospital acquired deep vein thrombosis or pulmonary embolism. NICE guideline 89. 2018. Available online: https://www.nice.org.uk/guidance/ng89

46. Vandermeulen EP, Van Aken H, Vermylen J. Anticoagulants and spinal-epidural anesthesia. Anesth Analg 1994;79:1165-77.

47. Batchelor TJP, Rasburn NJ, Abdelnour-Berchtold E, et al. Guidelines for enhanced recovery after lung surgery: recommendations of the Enhanced Recovery After Surgery (ERAS®) Society and the European Society of Thoracic Surgeons (ESTS). Eur J Cardiothorac Surg 2019;5 5:91-115.

48. Mandalà M, Falanga A, Roila F; ESMO Guidelines Working Group. Management of venous thromboembolism (VTE) in cancer patients: ESMO Clinical Practice Guidelines. Ann Oncol 2011;22 Suppl 6:vi85-vi92.

49. Ahmed AB, Koster A, Lance M, Faraoni D; ESA VTE Guidelines Task Force. European guidelines on perioperative venous thromboembolism prophylaxis: Cardiovascular and thoracic surgery. Eur J Anaesthesiol 2018;35:84-9.

50. Merkow RP, Bilimoria KY, McCarter MD, et al. Postdischarge venous thromboembolism after cancer surgery: extending the case for extended prophylaxis. Ann Surg 2011;254:131-7.

51. Hachey KJ, Hewes PD, Porter LP, et al. Caprini venous thromboembolism risk assessment permits selection for postdischarge prophylactic anticoagulation in patients with resectable lung cancer. J Thorac Cardiovasc Surg 2016;151:37-44.e1.

52. Rasmussen MS, Jorgensen LN, Wille-Jørgensen P, et al. Prolonged prophylaxis with dalteparin to prevent late thromboembolic complications in patients undergoing major abdominal surgery: a multicenter randomized openlabel study. J Thromb Haemost 2006;4:2384-90.

53. Rasmussen MS, Jørgensen LN, Wille-Jørgensen P. Prolonged thromboprophylaxis with low molecular 
weight heparin for abdominal or pelvic surgery. Cochrane Database Syst Rev 2009;(1):CD004318.

54. Caprini JA. Risk assessment as a guide for the prevention of the many faces of venous thromboembolism. Am J Surg. 2010;199:S3-S10.

55. Illinois Medical Society Resources for Patients/DVT. Available online: https://www.isms.org/dvt

56. Hachey KJ, Sterbling H, Choi DS, et al. Prevention of Postoperative Venous Thromboembolism in Thoracic Surgical Patients: Implementation and Evaluation of a Caprini Risk Assessment Protocol. J Am Coll Surg 2016;222:1019-27.

57. Rogers SO Jr, Kilaru RK, Hosokawa P, et al. Multivariable predictors of postoperative venous thromboembolic events after general and vascular surgery: results from the patient safety in surgery study. J Am Coll Surg 2007;204:1211-21.

58. Barbar S, Noventa F, Rossetto V, et al. A risk assessment model for the identification of hospitalized medical patients at risk for venous thromboembolism: the Padua Prediction Score. J Thromb Haemost 2010;8:2450-7.

59. Khorana AA, Dalal M, Lin J, et al. Incidence and predictors of venous thromboembolism (VTE) among ambulatory high-risk cancer patients undergoing chemotherapy in the United States. Cancer 2013;119:648-55.

60. Shah DR, Wang H, Bold RJ, et al. Nomograms to predict risk of in-hospital and post-discharge venous thromboembolism after abdominal and thoracic surgery: an American College of Surgeons National Surgical Quality Improvement Program analysis. J Surg Res 2013;183:462-71.

61. Novis SJ, Havelka GE, Ostrowski D, et al. Prevention of thromboembolic events in surgical patients through

doi: $10.21037 /$ shc-20-68

Cite this article as: Kolokotroni SM. Deep vein thrombosis and pulmonary embolism following lung resection. Shanghai Chest 2021;5:30. the creation and implementation of a computerized risk assessment program. J Vasc Surg 2010;51:648-54.

62. Kearon C, Akl EA, Ornelas J, et al. Antithrombotic Therapy for VTE Disease: CHEST Guideline and Expert Panel Report [published correction appears in Chest. 2016 Oct;150(4):988]. Chest 2016;149:315-52.

63. Kearon C, Akl EA, Comerota AJ, et al. Antithrombotic therapy for VTE disease: Antithrombotic Therapy and Prevention of Thrombosis, 9th ed: American College of Chest Physicians Evidence-Based Clinical Practice Guidelines [published correction appears in Chest. 2012 Dec;142(6):1698-1704]. Chest 2012;141:e419S-e496S.

64. Agnelli G, Becattini C. Acute pulmonary embolism. N Engl J Med 2010;363:266-74.

65. Simonneau G, Sors H, Charbonnier B, et al. A comparison of low-molecular-weight heparin with unfractionated heparin for acute pulmonary embolism. The THESEE Study Group. Tinzaparine ou Heparine Standard: Evaluations dans l'Embolie Pulmonaire. N Engl J Med 1997;337:663-9.

66. Van Schil PE, Hendriks JM, Lauwers P. Focus on treatment complications and optimal management surgery. Transl Lung Cancer Res 2014;3:181-6.

67. Stein PD, Alnas M, Beemath A, et al. Outcome of pulmonary embolectomy. Am J Cardiol 2007;99:421-3.

68. Madani M, Mayer E, Fadel E, et al. Pulmonary Endarterectomy. Patient Selection, Technical Challenges, and Outcomes. Ann Am Thorac Soc 2016;13 Suppl 3:S240-S247.

69. Thomas M, Shen KR. Coagulopathy and Anticoagulation During Thoracic Surgery. Thorac Surg Clin 2015;25:309-23. 